This PDF is a selection from a published volume from the National Bureau of Economic Research

Volume Title: Measuring and Managing Federal Financial Risk

Volume Author/Editor: Deborah Lucas, editor

Volume Publisher: University of Chicago Press

Volume ISBN: 0-226-49658-9

Volume URL: http://www.nber.org/books/luca07-1

Conference Date: February 8-9, 2007

Publication Date: February 2010

Chapter Title: Federal Financial Exposure to Natural Catastrophe Risk

Chapter Author: J. David Cummins, Michael Suher, George Zanjani

Chapter URL: http://www.nber.org/chapters/c3036

Chapter pages in book: $(61$ - 92) 


\title{
Federal Financial Exposure to Natural Catastrophe Risk
}

\author{
J. David Cummins, Michael Suher, and George Zanjani
}

\subsection{Introduction}

In the aftermath of the terrorist attacks of September 11, 2001, Congress passed supplemental appropriations of over $\$ 26$ billion for redevelopment, clean up, and aid to attack victims and their families. By the standards of the time, the nature and extent of the expenditures were unprecedented. However, the new standard would be broken only a few years later, when Congress appropriated emergency funds for over $\$ 80$ billion in disaster assistance in the aftermath of Hurricane Katrina and three other hurricanes, which all occurred in one four-month period.

Viewed in the context of federal disaster policy over the last century, the responses to September 11 and Hurricane Katrina fit well with a long-term trend of a continuously increasing federal role in disaster assistance (e.g., Moss 1999, 2002). Over twenty years ago, Kunreuther and Miller (1985) observed:

The role of the federal government with respect to hazards has been changing . . . there has also been a realization that government has been

J. David Cummins is the Joseph E. Boettner Professor of Risk Management, Insurance, and Financial Institutions at the Fox School of Business, Temple University. Michael Suher is a graduate student in economics at Brown University. George Zanjani is associate professor of Risk Management and Insurance at Georgia State University.

The views expressed in this chapter are those of the authors and do not necessarily represent the positions of Temple University, the Federal Reserve Bank of New York, the Federal Reserve System, Brown University, or Georgia State University. We would like to thank Karen Clark, Gary Kerney, Robert Klein, Deborah Lucas, Greg Niehaus, two anonymous reviewers, and participants at the NBER/Kellogg conference on Measuring and Managing Federal Financial Risk and the American Risk and Insurance Association (ARIA) 2007 annual meeting for their insightful comments. 
viewed as the protector of risks in ways that would have been unthinkable 50 years ago. Even 30 years ago there was a reluctance by local communities to rely on federal relief for recovery purposes.

Reactions to more recent disasters have revealed a telling shift in political sentiments at the state and local level. The response of Missouri Governor Mel Carnahan to calls for fiscal restraint in the aftermath of the Mississippi River flooding in $1993^{1}$ ("This is not the time for debating the fine points of long-term policy!") seems more representative of local opinion today. Moreover, development has been steadily increasing in catastrophe-prone areas, so the property at risk is far greater now than at any time in the past. ${ }^{2}$ Indeed, the subsidization of high-risk areas embedded in federal disaster policy has almost certainly encouraged development in those areas, thereby increasing federal exposure. ${ }^{3}$

The combination of rising standards for federal assistance and the growing private exposure suggests that the "stealth entitlement" of federal disaster assistance has grown large enough to merit a deeper assessment. Following Governor Carnahan's exhortation, we make no attempt in this chapter to dissect the "finer points" of public disaster policy. Instead, we set ourselves the more concrete objective of assessing the federal exposure. In other words, if we take as given the current generosity of federal disaster policy and the current state of development in catastrophe-prone areas, what is the taxpayer's expected annual bill for disaster-related expenditures? And what could the bill be in a bad year?

The numbers we estimate in answering the foregoing questions are significant. Based on the historical relationship between catastrophe damages and federal expenditures, together with prospective assessments of future catastrophe damages from (a) a leading catastrophe modeling firm, Applied Insurance Research (AIR), and (b) the projection of historical catastrophe loss data from Property Claims Services (PCS), we estimate the average expected bill for disaster assistance related to hurricanes, earthquakes, thunderstorms, and winter storms to be about $\$ 20$ billion a year. In a bad year, corresponding to a catastrophic event of severity expected only once every century, the bill could exceed $\$ 100$ billion. Conservative methods guide both estimates, so more liberal assumptions (e.g., extrapolating recent growth in federal generosity to the future instead of assuming no change) would yield considerably higher estimates.

To get a sense of the significance of these figures in relation to other, more familiar obligations of the Federal Government, we take the expected

1. Cited by Moss (1999, 259).

2. For example, the amount of property exposed to hurricane losses in Florida grew by 27 percent to \$2.5 trillion between 2004 and 2007. See Hartwig (2008).

3. This is an important moral hazard issue that is beyond the scope of the present chapter. It would be useful to explore the link between federal disaster policy and development in future research. 
annual expense over the next seventy-five years and compute a net present value (NPV) of this "unfunded liability." Doing so yields a figure between \$1.2 and \$7.1 trillion, depending on assumptions of growth and discount rates. For comparison, the trustees of Social Security project a shortfall with an NPV of \$4.9 trillion over this same horizon.

Even the conservative estimate of $\$ 20$ billion a year is far higher than the Federal Emergency Management Agency (FEMA) regular budget for disaster relief. Regular appropriations for the Disaster Relief Fund (DRF; the main vehicle for federal relief) averaged about $\$ 1$ billion over the fiscal years from 2001 to 2005, while supplemental appropriations to the Disaster Relief Fund averaged \$16.5 billion over the same period (GAO 2007). Our estimate of future relief spending is accurate enough to allow budgeting for disasters in the regular appropriation process.

The rest of this chapter is organized as follows. Section 4.2 offers background, including details on federal disaster policy. Section 4.3 discusses the methodology used for (a) assessing the relationship between federal disaster relief and catastrophe damages and (b) estimating the prospective distribution of aggregate catastrophe losses for the United States. Section 4.4 discusses the results, including the effects of modifying assumptions. Finally, section 4.5 concludes with a discussion of the policy implications of our findings.

\subsection{Background}

The Federal Government's financial exposure to catastrophic risk stems mainly from ad hoc disaster relief distributed to individuals, business, and communities; direct exposure of government facilities and service provision operations to disasters; and government insurance programs such as the $\mathrm{Na}-$ tional Flood Insurance Program (NFIP) and the Terrorism Risk Insurance Program (TRIP). We discuss each of these sources next.

\subsubsection{Disaster Relief}

Historically, disaster relief expenditures have been the most significant component of federal catastrophe exposure. One consequence of the seemingly ad hoc nature of the relief is that only a small portion of anticipated relief expenditures is contained in the budget. However, although the full extent of the federal obligation to assist may not be explicitly enumerated by legislation, history suggests that federal action is inevitable after major disasters; indeed, assistance seems discretionary in name only. In the words of Moss (1999, 334):

Disaster spending has become a political sacred cow. . . Again and again in the aftermath of disasters, representatives from the affected states have insisted that their constituents deserve no less than what other victims 
received and that the particular nature of their disaster might justify even more. Federal catastrophe coverage has thus been subject to a ratchetingup process.

The Stafford Emergency Assistance and Disaster Relief Act of 1988 and its antecedents, beginning with the Disaster Relief Act of 1950, guide the process for federal relief in the aftermath of catastrophes. The act formally requires the Federal Government to offer aid when state and local resources are overwhelmed by a major catastrophe. The Stafford Act designates FEMA to give declaration recommendations to the president after a disaster, and the Homeland Security Presidential Directive (HSPD)-5 makes the secretary of homeland security "responsible for coordinating Federal resources within the United States to prepare for, respond to, and recover from terrorist attacks, major disasters, and other emergencies" (DHS 2006b).

If the president makes a declaration, then FEMA is charged with overseeing the response, both directly and by administering funds to other federal agencies. The money comes from the DRF, a "no-year" account (i.e., any dollars appropriated remain available until expended) that receives annual appropriations though is largely reliant on supplemental appropriations from Congress in the event of major catastrophes.

The other sources of significant federal spending on disasters are the Small Business Administration (SBA), which makes subsidized disaster loans to households and businesses, and the US Department of Agriculture (USDA), which dispenses disaster loss funds to farmers. Most funding for the SBA is provided through its annual appropriations from Congress. The president may make a major disaster declaration or an emergency declaration. The latter is less significant and aims for federal costs not to exceed $\$ 5$ million. If the president makes a more substantial major disaster declaration, some types of available federal aid actually have Stafford Act mandated floors on the federal share of expenditures. These mandated floors include 75 percent of eligible costs for "essential assistance" and "debris removal" and 100 percent of "housing assistance" (Bea 2006).

\subsubsection{Exposures to Federal Facilities and Operations}

Federal Government property, such as military bases or Veterans Affairs (VA) hospitals, can be susceptible to direct physical damage from catastrophes. The Federal Government is also bound to provide certain everyday public services, including providing Social Security and Medicare benefits and running federal law and order institutions. The prompt resumption of these services postdisaster can entail significantly higher-than-normal operational costs (DHS 2006a).

\subsubsection{Insurance Programs}

The US Federal Government plays significant roles in disaster insurance markets. In particular, it essentially acts as the major underwriter of resi- 
dential flood insurance (through the NFIP, administered by FEMA); it also effectively acts as the country's largest reinsurer of terrorism risk through the TRIP.

The maximum government exposure under the TRIP is laid out by statute. For 2009 to 2014, the Federal Government is technically liable for up to $\$ 61.625$ billion of terrorism losses, of which some fraction may be recouped from the industry. ${ }^{4}$ To date, no losses have been paid under the TRIP. Of course, it is likely that the government's exposure to terrorism losses is significantly larger than the limits laid out in the TRIP. The government paid out approximately $\$ 16$ billion through the September 11 Victims' Compensation Fund of $2001,{ }^{5}$ and pressures for ad hoc payments are likely to develop if a terrorist event larger than the $\$ 100$ billion maximum under the TRIP were to occur.

The NFIP boasts about $\$ 1.1$ trillion in exposures nationally. ${ }^{6}$ Although it is described as a "self-financing" program, the NFIP has borrowing rights at the Treasury when losses exceed its resources. This borrowing authority was increased dramatically to $\$ 20.8$ billion to cover claims following Hurricane Katrina. In reality, the NFIP is not self-supporting and has been criticized for leaving a high proportion of flood-exposed properties uninsured and not operating on sound actuarial principles (Cummins 2006; Jenkins 2006). Hence, in its present form, the NFIP creates more financial exposure for the Federal Treasury than was envisioned when the program was established.

Other federal insurance programs are also exposed to catastrophe losses. Notably, the US Department of Agriculture insured \$50 billion of crop value in 2006 through the Federal Crop Insurance Corporation (Federal Crop Insurance Corporation 2007).

\subsubsection{Additional Sources of Exposure}

The aftermath of a major catastrophe will entail significant economic disruption for the affected region and potentially for entire national industries. Lost jobs, reduced wages, and lower output will all result in a lower tax base. This means less federal revenue at a time of increased federal spending. Government postdisaster aid will contribute to rebuilding the tax base and thus over the long run will lessen the size of indirect exposure created by lost tax revenues.

Next, we describe our collection and analysis of data on federal disaster expenditures and catastrophe losses.

4. The figure of $\$ 61.625$ billion is obtained by multiplying the federal coinsurance share for 2007 to 2014 ( 85 percent) by $\$ 72.5$ billion (calculated as the maximum insured loss amount of $\$ 100$ billion less the aggregate industry retention of $\$ 27.5$ billion). See Dunham and Dembeck (2008).

5. Victims' compensation is not explicitly part of the TRIP, which primarily provides reinsurance for property-casualty insurance coverages. Data on September 11 victims' compensation are from the following website: http://www.usdoj.gov/archive/victimcompensation/payments _deceased.html.

6. See: http://www.fema.gov/business/nfip/statistics/cy2007cov.shtm. 


\subsection{Data and Methodology}

As noted previously, ad hoc disaster assistance has historically been the most important source of direct federal financial exposure to catastrophes. Hence, the remainder of the chapter focuses on that component of exposure. We use data on disaster damages and disaster assistance to project the distribution of expected federal disaster relief expenditures.

There are three basic steps to this analysis. The first step is to document the relationship between catastrophe damages and federal relief expenditures over the period from 1989 to 2008 to estimate the amount of federal relief expenditures likely to be "produced" by catastrophe losses. The second step is to develop a prospective annual catastrophe loss distribution for the United States. The third and final step, performed in the results section, is to apply the estimated ratio of federal relief expenditures to catastrophe damages (obtained in the first step) to the estimated catastrophe damage distribution (obtained in the second step) to produce an estimated annual federal disaster expenditure distribution for the United States. In this step, we also calculate the net present value of the implicit government liability arising from catastrophe losses.

\subsubsection{Data on the Relationship between Catastrophe Loss and Federal Disaster Relief}

We combine loss estimates for recent catastrophes with figures for emergency supplemental appropriations to assess the generosity of postdisaster federal aid.

We restrict our attention to catastrophes with at least $\$ 1$ billion in total damages (in nominal terms) between 1989 and 2008. The main source for total damage estimates is data from the National Oceanic and Atmospheric Administration's (NOAA) National Climactic Data Center (NCDC) and Munich Re (2008, 2009). For each catastrophe, we also identify insured losses using the Insurance Services Office's (ISO) Property Claims Services estimates of privately insured losses and the National Flood Insurance Program payouts for flood losses under the NFIP. Our selection criterion yields sixty-five events, with the majority being hurricanes and tropical storms. Also included are the Loma Prieta, Northridge, and Nisqually earthquakes; ${ }^{7}$ the Oklahoma City and September 11 terrorist attacks; ${ }^{8}$ and various significant floods, storms, and wildfires. ${ }^{9}$ As the NOAA relates, unlike with private

7. Total losses for the Loma Prieta and Northridge earthquakes, described as overall losses in the entire affected region, come from Munich Re (2005). Total losses for the Nisqually earthquake come from Meszaros and Fiegener (2002).

8. Oklahoma City bombing total damage figure comes from "Governor, Finance Director Release Bomb Damage Estimates," press release from the Office of Governor Frank Keating. Available at: http://www.state.ok.us/osfdocs/nr5-18.html. September 11 total damage figure comes from Bram, Orr, and Rapaport (2002).

9. The NOAA damage estimates are used for all events except the three earthquakes, the Oklahoma City bombing, and the September 11 terrorist attacks. 
and NFIP insured losses, where every dollar paid out in claims is recorded, there is no federal agency tasked with keeping track of total losses resulting from catastrophes in the United States.

The NOAA bases its estimates on compilations of statistics from Storm Data (NCDC publication), the National Weather Service, the Federal Emergency Management Agency, other U.S. government agencies, individual state emergency management agencies, state and regional climate centers, and insurance industry estimates. ${ }^{10}$ The figures from the NOAA and the others we use for total damages always encompass insured and uninsured property damages. For longer duration events, like the 1993 Mississippi Flood, droughts, and the earthquakes in our sample, our total loss figures include additional economic costs, such as reduced agricultural output. In the case of September 11, our total loss figure explicitly includes economic costs associated with labor losses. The catastrophes, with the associated estimates of total and insured losses, are summarized in figures 4.1 and 4.2, where figure 4.1 presents nominal losses and figure 4.2 presents exposure and price-adjusted losses.

The gap between insured and total losses is, of course, significant. In the case of earthquakes, this can be attributed partly to low rates of earthquake insurance purchase; similarly, in the case of hurricanes and tropical storms, significant amounts of damage can result from flood - and many households are either uninsured or only partially insured against flood. Deductibles, coinsurance, and uninsured damages (e.g., certain "economic costs" just described) further contribute to insured losses being substantially below our estimate of total losses. For the entire sample of sixty-five events, the ratio of insured to total loss averages less than 50 percent.

For federal expenditures, we only use figures for emergency supplemental appropriations for disaster assistance. This is legislation outside of the regular annual budgeting process. By our estimates, it accounts for about 80 percent of all federal disaster spending over the period, as we discuss next. The money can go to any agency involved in relief, but the majority is provided through FEMA's Disaster Relief Fund. The appropriations include funds for disaster relief, repair of federal facilities, and hazard mitigation activities directed towards reducing the effects of future disasters. Not included are funds for "counterterrorism, law enforcement, and national security" (Murray 2006, p. 2).

It should be noted that the narrow focus on supplemental appropriations ignores some elements of federal financial exposure to disasters. We do not include the budgeted portion of federal disaster spending, which covers annual appropriations to FEMA's Disaster Relief Fund, much of the

10. The National Oceanic and Atmospheric Administration describes their estimates of total costs as "the costs in terms of dollars and lives that would not have been incurred had the event not taken place. Insured and uninsured losses are included in damage estimates. . . . Economic costs are included for wide-scale, long-lasting events such as drought" (Lott and Ross 2006, p. 1). 
A

Northeast Ice Storm (Jan-98) $\square 1,4$

Northern Flains Flooding (May -97)

MS/OH Flooding/Tornadoes (Mar-97) P 1.0

West Coast Flooding (Jan-96)

Hurric ane Fran (5ep-96)

Pacific NW Frooding (Feb-96)

Blizzard of ' 26 (jan-9.6)

Hurricane Opal (Oct-95')

Hurricane Marilyn (Sep-95)

SE Severe weather/Flooding (May-95]

Oklahoma City Bembing (Apr-95]

Califormia Flooding [Feb-95)

Texas. Flooding (Oct-94]

Tropical storm Alberto (Jut-94)

Northridge Earthquake (Jan-94

southeast Ice 5 torm (Feb-94]

Califorria Wildfires [Oct-93)

Midwest Flooding [Jul-93.

Storm/Blizzard ( $/ \mathrm{M}^{\prime}$ ar-93)

Nor'easter of 1992 (Dec-92)

Hurricane Iniki (Sep-92)

Hurricane Andrew (Aug-92)

Oakland Firestorm (oct-91)

Hurricane Bob (Aug-91)

5outherm Plains Flooding (May-90)

Loma Prieta Earthquake (Oc4-89) Hurricane Hugo (Sep 89 )

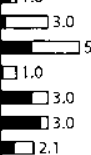

$\square 3.0$

口2.1

$\square 5.5$

3.0

01.0

10

$\square .0$

01.0

5.5

D 1.5

1.8

$\square 2.5$

$\square 1.5$

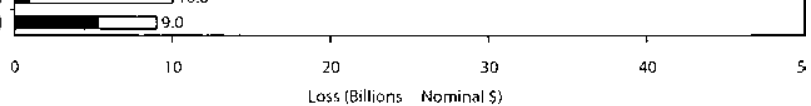

DTotal Los D Disurcd Loss

B

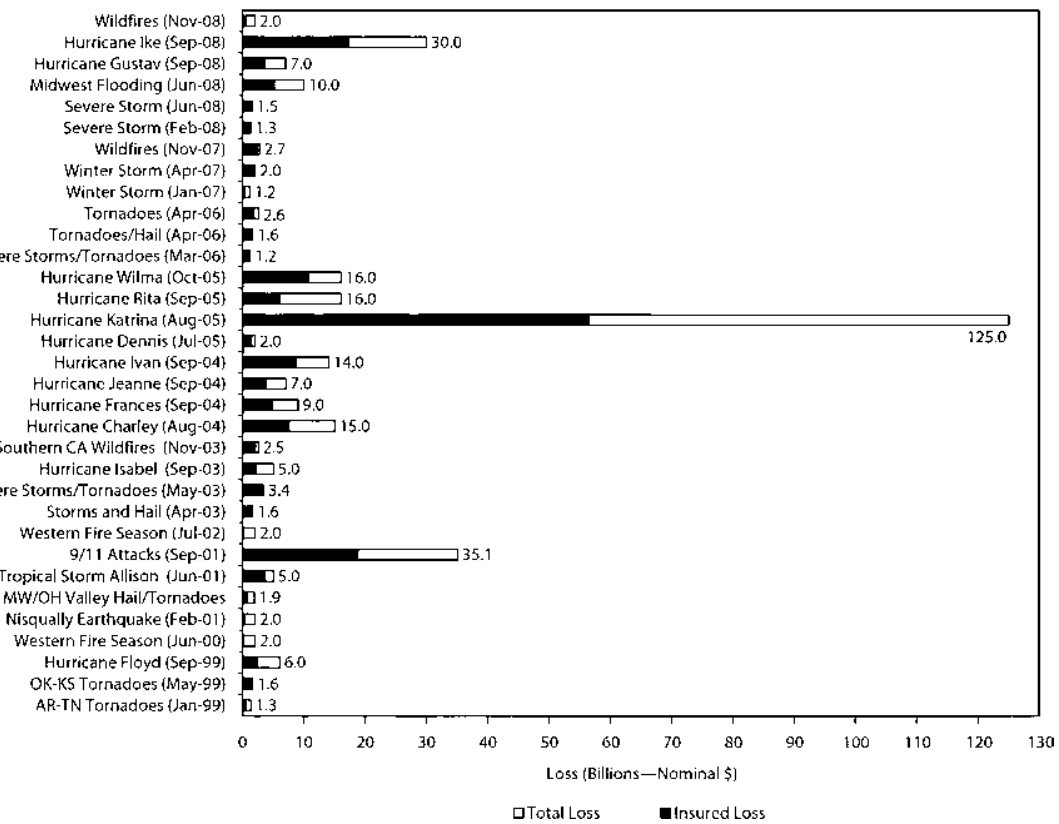

Fig. 4.1 Sample of major disasters, nominal losses: $A, 1989-1998 ; B, 1999-2008$ 
A

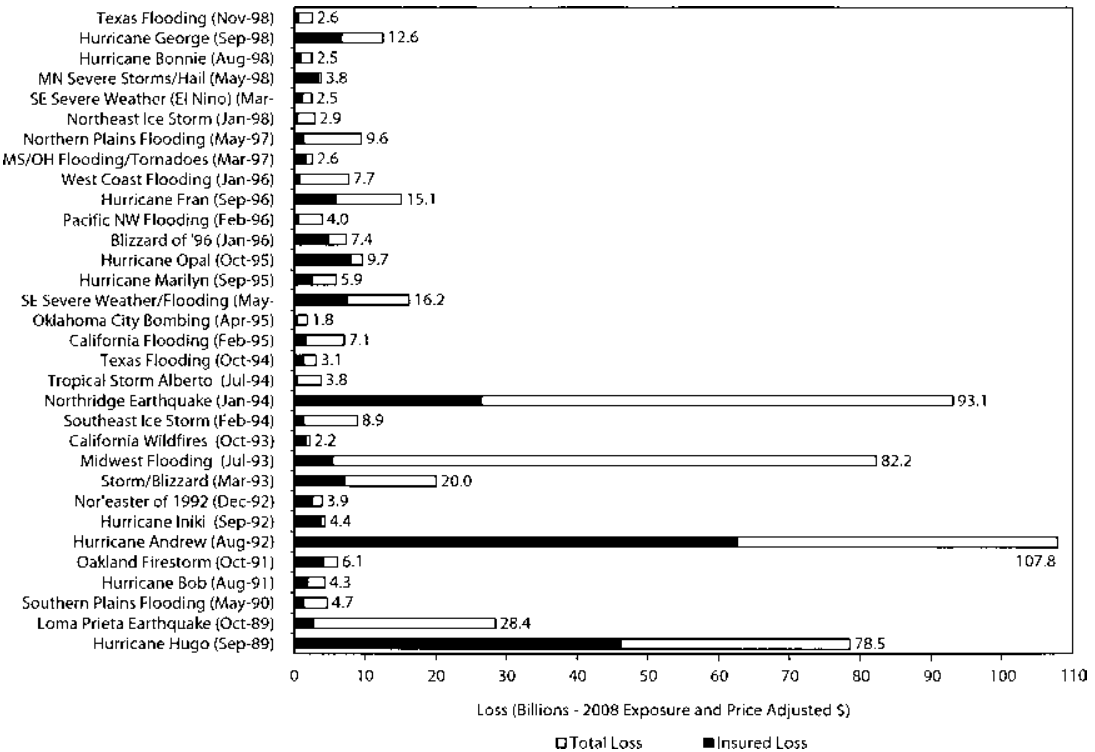

B

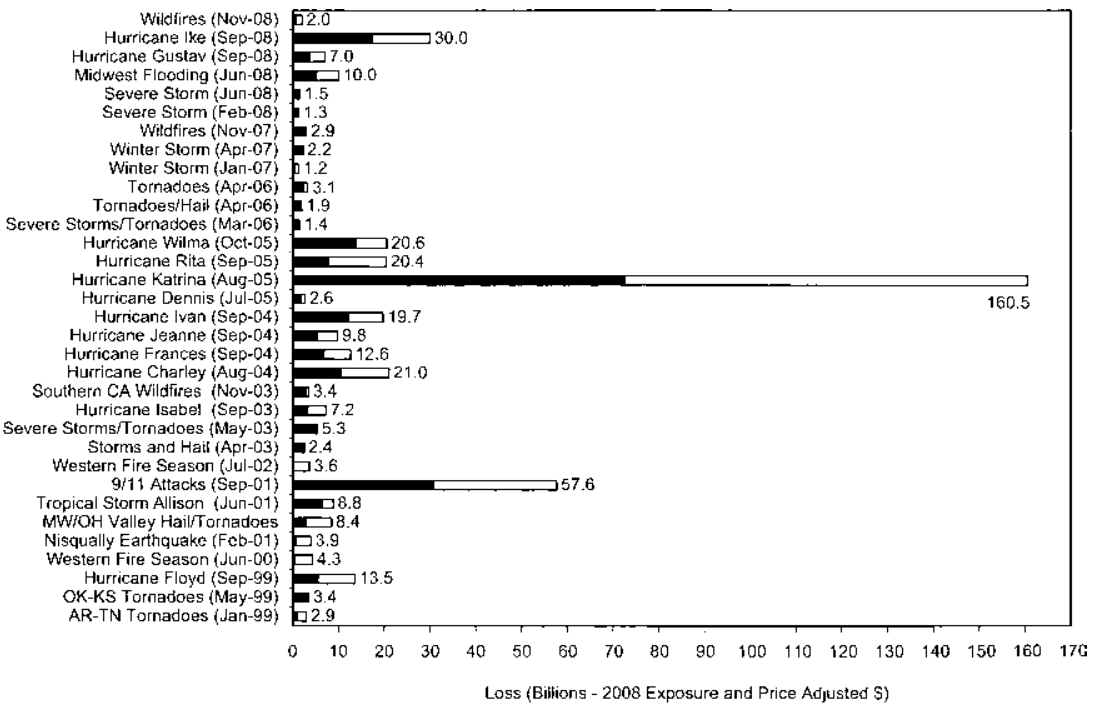

口Tolal Loss $\quad$ Instured Loss

Fig. 4.2 Sample of major disasters, exposure and price adjusted losses: $A$, 19891998; $B, 1999-2008$

Note: Insured and total loss figures are adjusted at the state level by our 2008 exposure index. This index captures both price-level changes and changes in the size of the housing stock. The intent is to estimate the losses a past disaster would cause if it occurred today. 
Small Business Administration's subsidized disaster loans program, and reconstruction projects that take place long after the fact. Also not included are farm and economic supplemental appropriations through the USDA for specifically agricultural disasters, like droughts. Total USDA spending on farm disaster aid totaled $\$ 54.4$ billion over this time horizon. ${ }^{11}$ We also treat NFIP losses as insurance payments and thus exclude them from the expenditure data. Of course, a case could be made for including them: while the program was close to being self-financing through 2004 (at which point the NFIP had aggregated only a $\$ 200$ million deficit), the picture looked far different after record flood losses of the 2005 hurricane season, when the cumulative deficit of losses over premiums was $\$ 4.9$ billion. Although the deficit was reduced to $\$ 556$ million by 2007 , the program is unlikely to be self-supporting in the long run and is badly in need of reform. ${ }^{12}$

Other special items are also excluded: for example, in the case of the 2001 terrorist attacks, we have not included the billions in indemnification distributed through the Victims' Compensation Fund. In summary, our figures for total federal disaster expenditures capture a significant portion, but not all, of the nonbudgeted federal exposure to disaster risk; furthermore, we do not attempt to capture exposures that are already reflected in the budget.

We draw on the Congressional Research Service analysis of appropriations, the text of the aid legislation, and the date of catastrophe occurrence to assign aid to catastrophes. ${ }^{13}$ The appropriation legislation for disasters is usually part of larger bills, and often money is earmarked for multiple recent disasters. This fact, combined with the large number of hurricanes in the sample, make drawing inferences by catastrophe type difficult. Instead, we focus on all the events together.

Figure 4.3 shows the ratio of federal expenditures to total losses. The ratio of aid to total losses has a mean of 33 percent and a median of 30 percent, and the ratio of aid to uninsured losses has a mean of 101 percent and a median of 64 percent. In aggregate, the sixty-five events, in values adjusted to 2008 exposure and price levels, comprise about $\$ 1.1$ trillion in total losses, $\$ 450$ billion in insured losses, and $\$ 375$ billion in emergency spending. These aggregated figures are summarized in table 4.1 (panel B).

While there is significant volatility in the aid ratios across the sample,

11. Chite (2006). See also Murray and Lindsay (2008).

12. Data are from the FEMA website (http://www.fema.gov/business/nfip/statistics/statscal .shtm) and represent cumulative premiums minus cumulative losses from 1978 to 2007. Statements about FEMA being self-supporting are usually based on a comparison of premiums and loss payments. However, this comparison is misleading, because it ignores program expenses. Hence, even during periods when premiums exceed loss payments, it is not necessarily the case that the program is truly self-supporting.

13. Appropriation legislation is sometimes explicit in assigning particular dollars to a particular catastrophe or set of catastrophes, in which case the allocation is straightforward. In other cases, legislation appropriates funds for unspecified catastrophes in the future, in which case the date of occurrence is relevant for assignment. 


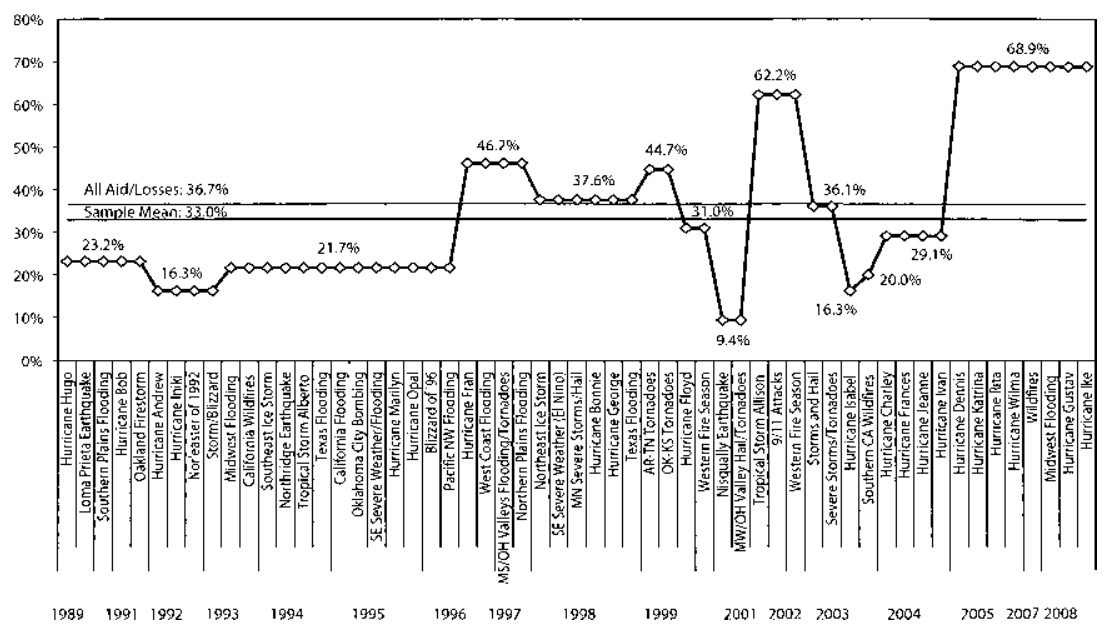

Fig. 4.3 Federal aid ratios: 1989 to 2008

Note: Each data point represents a specific disaster in our sample, with labels for the most significant disasters. The "all aid/losses" ratio is computed after adjusting loss and aid figures by our 2008 exposure index. This index captures both price-level changes and changes in the size of the housing stock. This yields a ratio that is not overweighted by recent disasters.

there is some evidence of an increase in generosity over time: emergency federal aid/total losses for $9 / 11$ and surrounding natural disasters was 62 percent, even though federal aid did not breach 50 percent of total loss for any of the previous events in the sample. Beginning in the 2005 hurricane season and continuing through 2008, federal aid averaged 69 percent of total losses. ${ }^{14}$

To obtain a more comprehensive picture of Federal Government spending on disaster aid, we tabulate annual total federal disaster spending and compare it to annual catastrophe losses for fiscal years from 1989 to 2008. The data are presented in table 4.1 and figure 4.4. In addition to the emergency supplemental appropriations previously discussed, we include regular annual appropriations to FEMA's Disaster Relief Fund, USDA emergency funding for agriculture disasters, ${ }^{15}$ and the subsidization cost of SBA disaster loans. ${ }^{16}$ Annual catastrophe losses are comprised of NOAA's billion-dollar weather events; the Loma Prieta, Northridge, and Nisqually earthquakes; and the Oklahoma City and September 11 terrorist attacks. Over this span, in values adjusted to 2008 exposure and price levels, we observe $\$ 512$ billion

14. It is difficult to distinguish the level of funding for the specific events during this period, because the Congressional acts authorizing the payments tended to lump together funding for several events rather than distinguishing specific funding per event.

15. Funding for "market loss payments to compensate for low farm commodity prices" is excluded.

16. Emergency supplemental figures are adjusted to avoid double counting for some SBA disaster loan subsidies and DRF original appropriations. 
Table 4.1

Summary of catastrophe loss and federal aid: 1989 to 2008

Panel A-Values in billions: Nominal \$

\begin{tabular}{|c|c|c|c|c|}
\hline Aggregate & & & Mean & Median \\
\hline \multicolumn{5}{|c|}{ Emergency supplemental appropriations by event } \\
\hline Number of events & 65 & Aid to total loss & $33.0 \%$ & $30.1 \%$ \\
\hline Total loss & 510.0 & Insured loss to total & $45.7 \%$ & $44.6 \%$ \\
\hline Insured loss (including NFIP) & 235.9 & Aid to uninsured loss & $101.4 \%$ & $63.8 \%$ \\
\hline NFIP & 27.2 & & & \\
\hline Federal aid & 240.6 & & & \\
\hline Aid to total loss & $47.2 \%$ & & & \\
\hline Insured loss to total & $46.3 \%$ & & & \\
\hline Aid to uninsured loss & $87.8 \%$ & & & \\
\hline \multicolumn{5}{|c|}{ Total federal disaster spending by year } \\
\hline Number of years & 20 & Aid to total loss & $62.0 \%$ & $55.7 \%$ \\
\hline Total loss & 542.1 & & & \\
\hline NFIP & 32.9 & & & \\
\hline Federal aid & 285.7 & & & \\
\hline Aid to total loss & $52.7 \%$ & & & \\
\hline
\end{tabular}

Panel B-Values in billions: 2008 exposure and price adjusted \$

\begin{tabular}{|c|c|c|c|c|}
\hline \multicolumn{3}{|l|}{ Aggregate } & Mean & Median \\
\hline \multicolumn{5}{|c|}{ Emergency supplemental appropriations by event } \\
\hline Number of events & 65 & Aid to total loss & $33.0 \%$ & $30.1 \%$ \\
\hline Total loss & $1,021.9$ & Insured loss to total & $45.7 \%$ & $44.6 \%$ \\
\hline Insured loss (including NFIP) & 449.9 & Aid to uninsured loss & $101.4 \%$ & $63.8 \%$ \\
\hline NFIP & 44.2 & & & \\
\hline Federal aid & 374.7 & & & \\
\hline Aid to total loss & $36.7 \%$ & & & \\
\hline Insured loss to total & $44.0 \%$ & & & \\
\hline Aid to uninsured loss & $65.5 \%$ & & & \\
\hline \multicolumn{5}{|c|}{ Total federal disaster spending by year } \\
\hline Number of years & 20 & Aid to total loss & $62.0 \%$ & $55.7 \%$ \\
\hline Total loss & $1,136.6$ & & & \\
\hline NFIP & 59.8 & & & \\
\hline Federal aid & 511.8 & & & \\
\hline Aid to total loss & $45.0 \%$ & & & \\
\hline
\end{tabular}

Note: In panel B, loss figures are adjusted at the state level by our 2008 exposure index. This index captures both price-level changes and changes in the size of the housing stock. The intent is to estimate the losses a past disaster would cause if it occurred today. Federal disaster spending is also adjusted using the same index, which yields an aggregate aid ratio that is not overweighted by recent disasters. 

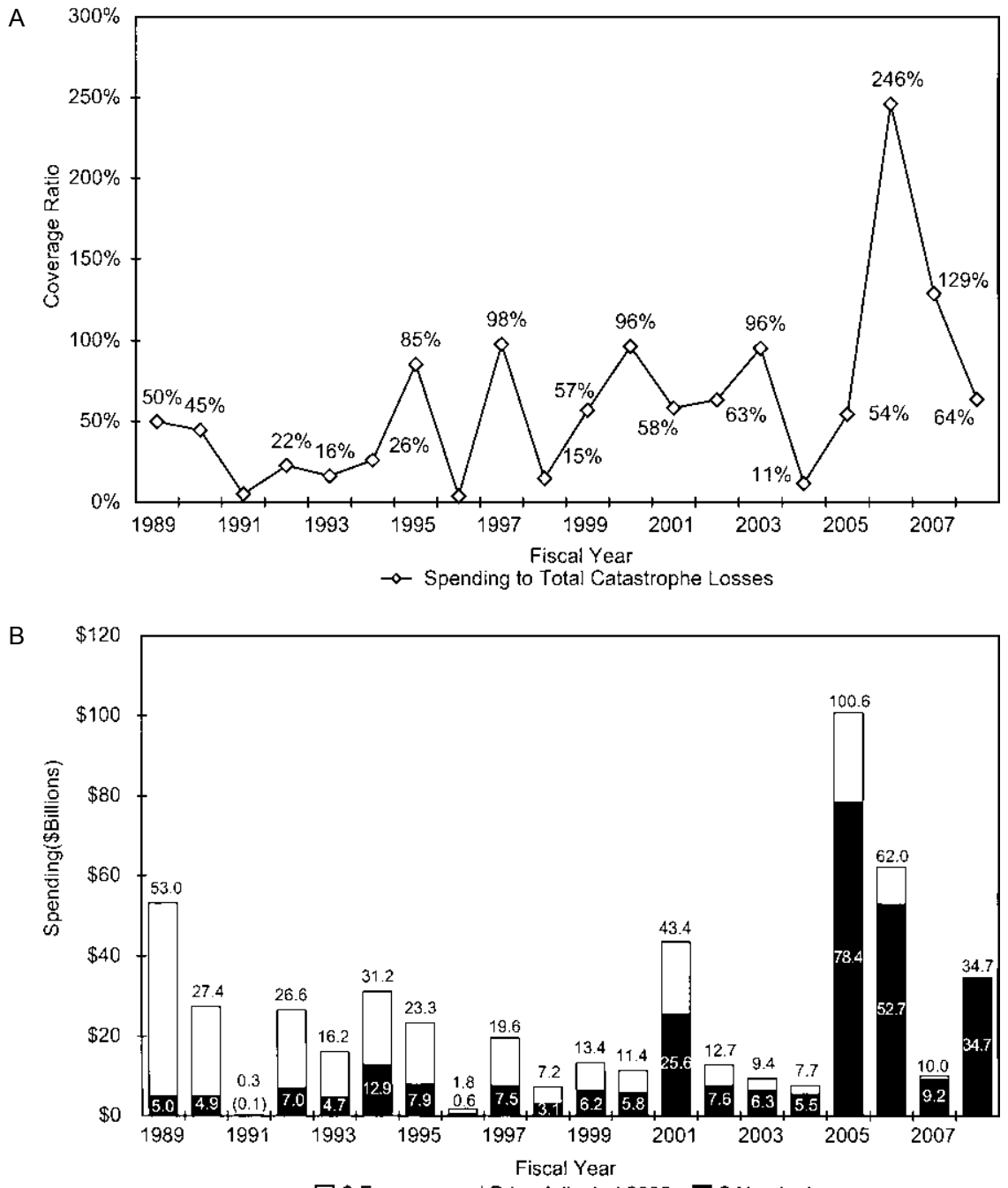

$\square \$$ Exposure and Price Adjusted 2008

\section{Fig. 4.4 Total federal disaster spending: FY1989 to FY2008}

Note: In panel B, values are adjusted at the state level by our 2008 exposure index. This index captures both price-level changes and changes in the size of the housing stock. The intent is to estimate the spending that would have resulted if a past disaster occurred today.

in total disaster spending and $\$ 1.1$ trillion in catastrophe losses, ${ }^{17}$ for a coverage ratio of 45 percent. It should be noted that the annual coverage ratios in

17. The main distinction between the catastrophe losses used in this calculation relative to those used previously relates to the inclusion of drought losses. This augmentation is necessary due to the inclusion of the USDA expenditures. 
figure 4.4 are partially misleading, as spending on a major disaster typically is spread over more than one year.

We now proceed to discuss projections of the catastrophe loss distribution for the entire United States, which will form the other half of the estimate of the Federal Government's catastrophe loss exposure.

\subsubsection{Data on the Aggregate Catastrophe Loss \\ Distribution for the United States}

The prospective catastrophe loss distribution for the United States is obviously difficult to estimate precisely, but a rough sense of its character is essential for our exercise. We use two methods to project the distribution.

The first method starts with the prospective distribution of catastrophe losses from a leading catastrophe modeling firm, Applied Insurance Research. We make adjustments to AIR's distribution to account for uninsured losses (e.g., such as flood losses incurred in hurricanes).

The second method starts with ISO's Property Claims Services database, which contains data on insured losses from US catastrophes spanning more than five decades. We then adjust the historical figures to account for changes in property exposure and price levels. We also make adjustments to account for insurance penetration rates and uninsured losses. The methodology for these adjustments is described next.

In both methods, we restrict our attention to natural catastrophes, such as hurricanes and earthquakes. This leads to a conservative estimate (in the sense of being smaller than what is likely) of catastrophe exposure in two respects. First, we omit man-made catastrophes such as terrorist attacks, oil spills, oil platform fires and explosions, and nuclear power accidents. Second, our methodology almost certainly neglects to fully reflect catastrophe exposure from flooding, since our data sources are focused on privately insured losses. While we have made adjustments to events in the data to reflect the presence of uninsured flood losses, these adjustments are applied only to events that produced significant insured losses (such as a tropical storm). Such a methodology understates flood exposure by failing to account for events with significant flooding but insignificant wind involvement.

\subsubsection{Aggregate Catastrophe Loss Distribution Based on the AIR Model}

Catastrophe modeling is recognized globally as the standard technique for risk assessment and management. It is utilized by insurers and other firms exposed to catastrophic risk in pricing, risk selection and underwriting, loss mitigation, reinsurance decision making, and overall portfolio management. Applied Insurance Research Worldwide, which provided the catastrophic loss estimates discussed here, is one of the three global leaders in catastrophe modeling. Although catastrophe modeling began in the 1980s, the develop- 
ment of the technology accelerated following Hurricane Andrew in 1992 and the Northridge earthquake in 1994.

The AIR model is a stochastic simulation model that incorporates mathematical representations of the natural occurrence patterns and characteristics of hurricanes, earthquakes, and other catastrophes..$^{18}$ The model incorporates meteorological and seismological data, actuarial loss data, and information on property values, construction types, and occupancy classes (classifications that indicate what the structure is being used for, such as residential, retail, etc.). In most major geographical areas, the AIR model maps insurer exposure to catastrophic losses to the level of the individual building structure. Incorporated in the model are property characteristics and insurance coverage parameters. Thus, the model provides simulated loss distributions for individual insurers in finely divided geographical areas.

The structure of the AIR model is shown in figure 4.5. The simulations begin with event generation, which entails random generation of events in terms of their location, frequency of occurrence, and severity. The simulations incorporate probability distributions based on historical data for each variable that defines the events. By sampling from these distributions, a large stochastic catalogue of simulated event scenarios is generated. This process is represented schematically in figure 4.6 for the simulation of hurricanes.

To estimate the damage potential of natural hazards, the model estimates their physical parameters, not only at the source but also at the sites of the affected building inventory. The local intensity part of the model's hazard module is designed to capture how intensity changes as the simulated catastrophe propagates or travels over the affected area. Detailed scientific and geophysical data and algorithms are employed to model the local effects of each simulated event.

The damage estimation or vulnerability component of the model superimposes the local intensities of each simulated event onto a database of exposed properties and estimates the expected level of damage to buildings and their contents. Loss estimates are based on region-specific damage functions for many different construction types and occupancies. Total damage estimates can be generated for the entire insurance industry, for individual insurer policy portfolios, or for individual buildings.

In the final component of the model, insured losses are calculated by applying specific insurance policy conditions to the total damage estimates. Policy conditions include deductibles by coverage, coverage limits and sublimits, coinsurance, and other policy conditions. The output of the model is an estimated loss distribution for a specific insurance portfolio and location, often presented as an exceedance probability curve that plots the probability of exceeding various loss amounts.

For purposes of the present study, AIR provided expected average losses

18. The discussion of the AIR model is based on Clark (2004). 


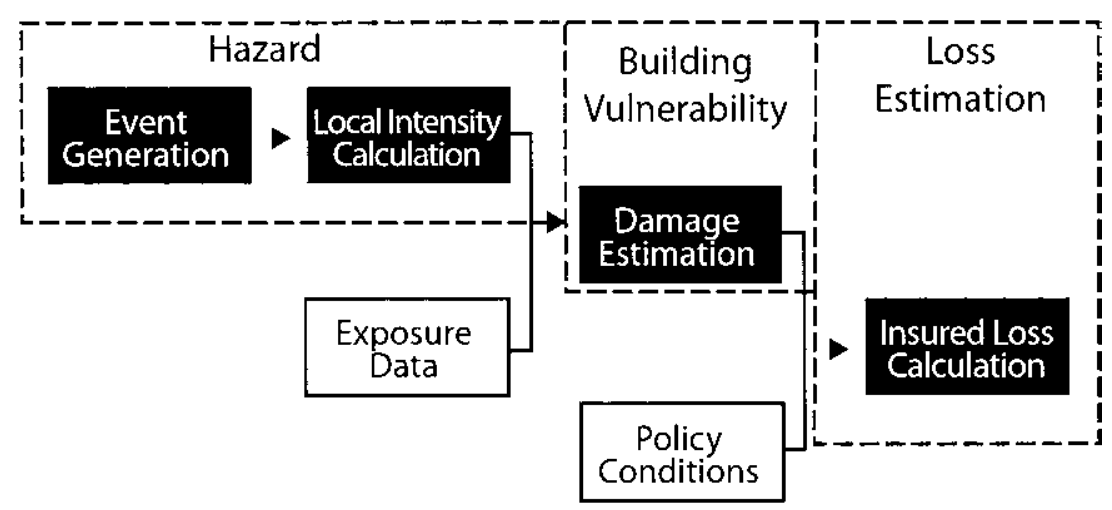

Fig. 4.5 The structure of the AIR simulation model

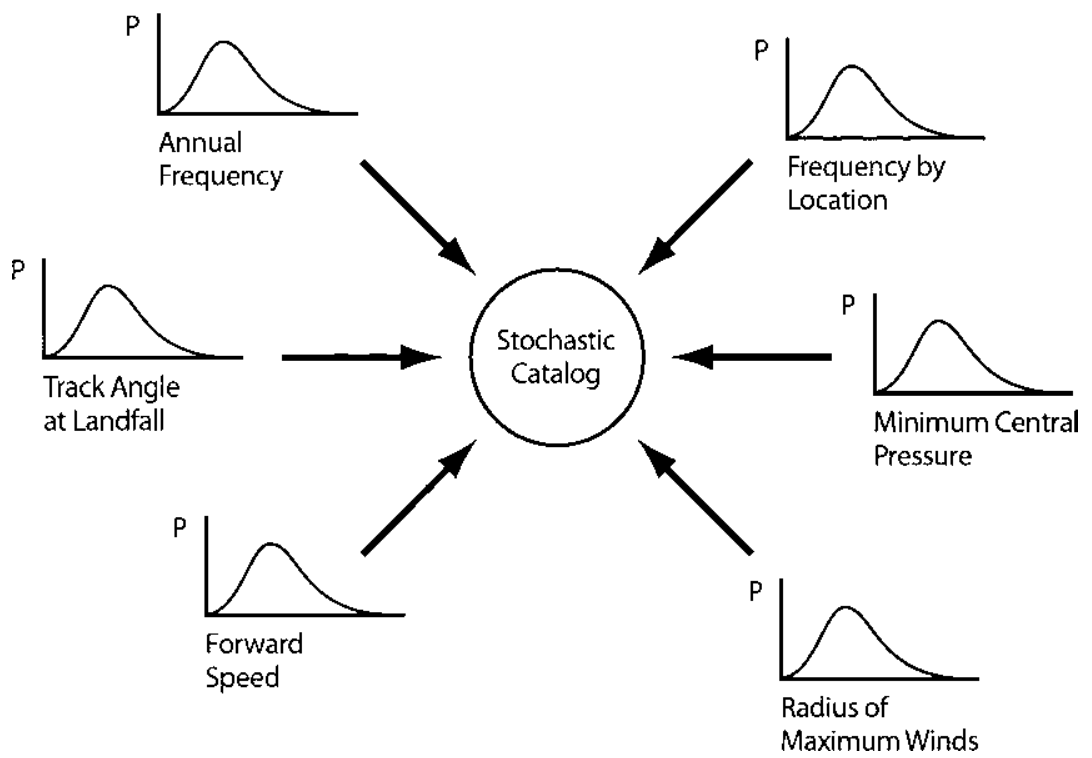

Fig. 4.6 Simulating a stochastic catalogue of storm events

and the higher percentiles, in aggregate and by occurrence, for hurricane, earthquake, winter storm, and severe thunderstorm. For all perils except earthquake, the estimates project insured losses, while the earthquake projection addresses insurable losses. As a result, AIR estimates of insured losses for perils other than earthquake will differ from total losses because of deductibles, policy limits, and uninsured losses. Accordingly, we adjust losses for the hurricane, thunderstorm, and winter storm perils upward to account for the historical relation between insured losses and total property losses observed in our sample of catastrophes. The intention is, to the extent 
possible, to adjust the AIR output to a basis consistent with the total loss estimates used in the previous section. However, we do not attempt to adjust the earthquake losses to reflect uninsured economic costs absent from the AIR calculations. As a result, the loss estimates should be lower than those that would be fully consistent with the "total losses" used in the previous section. Hence, our ultimate projections of total loss exposure from the AIR model will be conservative in the sense of yielding estimates of federal exposure that are probably on the low side.

Table 4.2 summarizes the average annual aggregate and occurrence losses produced by adjusting the AIR losses as described. In addition, we list the ninety-ninth percentile for all cases - the amount of loss corresponding to that expected with a frequency of once per century. ${ }^{19}$ The estimates show an annual aggregate expected average total loss of 35 to 43 billion dollars. The higher figure uses a shorter historical time series of hurricanes to account for the recent trend of more frequent and severe hurricanes. For all perils, there is a 1 percent chance of an annual loss of at least 273 to 282 billion dollars (without attempting the adjustment to hurricane and thunderstorm losses described previously). ${ }^{20}$

\subsubsection{Aggregate Catastrophe Loss Distribution Based on PCS Data}

In this section, we discuss the estimation of catastrophe loss distributions using the PCS data on insured catastrophe losses. The PCS reports losses at the state level, beginning in 1949, for various types of catastrophes. We adjust the data for changing exposure levels, as explained next, to provide estimates of the losses that would have resulted from the historical catastrophes recorded by the PCS if today's property values had existed at the time of the events. Maximum likelihood estimation is used to fit the adjusted losses to underlying parametric loss distributions. In this fashion, we can project expected losses and various percentiles to compare with the figures provided by AIR.

\subsubsection{Data Considerations}

Property Claims Services, a division of the Insurance Services Office, compiles data on insured losses from catastrophes. Currently, the PCS defines a catastrophe as an event that causes $\$ 25$ million or more in damages and

19. Note that the figures for the percentiles for the all perils category do not contain adjustments for the historical relationship between insured losses and total property losses, as we do not have detailed information on the composition of the all perils distribution. The average, however, does reflect the adjustment.

20. This figure represents the ninety-ninth percentile of the distribution of the sum of insured losses for all perils except earthquake and insurable losses for earthquake. Since we do not have the composition of the all perils distribution, we cannot make the referenced adjustments without making further assumptions. In the case of the average, however, the adjustments yielded an increase of about 50 percent; a similar impact on the ninety-ninth percentile would suggest a figure above $\$ 400$ billion. 
Table 4.2

AIR based projections of US catastrophe loss exposure

\begin{tabular}{lcr}
\hline & Aggregate & Occurrence \\
\hline All perils (standard hurricane model) & & \\
$\quad$ Expected average loss & 35.2 & 21.6 \\
$\quad$ 99th percentile & 272.6 & 234.6 \\
All perils (Near-term hurricane sensitivity) & & \\
$\quad$ Expected average loss & 43.1 & 27.7 \\
$\quad$ 99th percentile & 281.6 & 240.3 \\
Hurricane (standard model) & & \\
$\quad$ Expected average loss & 19.9 & 16.8 \\
$\quad$ 99th percentile & 109.0 & 97.4 \\
Hurricane (near-term sensitivity) & & 27.8 \\
$\quad$ Expected average loss & 138.7 & 122.0 \\
$\quad$ 99th percentile & & \\
Earthquake & 16.3 & 14.7 \\
$\quad$ Expected average loss & 238.2 & 213.8 \\
$\quad$ 99th percentile & & \\
Winter storm & 4.1 & 2.0 \\
$\quad$ Expected average loss & 8.8 & 5.5 \\
$\quad$ 99th percentile & & \\
Severe thunderstorm & 11.2 & 2.8 \\
$\quad$ Expected average loss & 19.7 & 10.3 \\
99th percentile &
\end{tabular}

Note: Perils include hurricane, earthquake, winter storm, severe thunderstorm, and implicitly, flood. Hurricane expected average loss scaled by 47.7 percent insured-to-total-loss ratio. Severe thunderstorm expected average loss scaled by 74.3 percent insured-to-total-loss ratio. Winter storm expected average loss scaled by 55.6 percent insured-to-total-loss ratio. Amounts in billions of dollars. An occurrence loss is the largest loss from a single simulated event in a given year, and the aggregate loss is the sum of losses from all simulated events in a given year.

${ }^{a}$ Near-term hurricane sensitivity uses a shorter historical time series of hurricanes to account for the recent trend of more frequent and severe hurricanes.

affects a significant number of policy holders. ${ }^{21}$ The PCS loss estimates are for personal and commercial property along with vehicle losses covered by comprehensive coverage. ${ }^{22}$ The data are collected by canvassing the insurance industry following major loss events and conducting supplemental field research in some instances. ${ }^{23}$ The PCS maintains data from 1949 through the present, broken down by state and by type of event. The PCS analysis in this chapter focuses on the period from 1950 through 2006.

In this study, we develop models based on fitting probability distributions

21. The monetary threshold used by the PCS to define a catastrophe has been adjusted over time. From 1949 to 1981, the dollar threshold was \$1 million; from 1982 to 1996, the threshold was \$5 million; and since 1997, the threshold has been \$25 million.

22. Auto losses generally represent 10 percent or less of total losses from catastrophes (e-mail from Gary Kerney of the PCS).

23. The PCS generally combines two methods to develop the best estimate of insured catastrophe losses. First, the PCS conducts confidential surveys of insurers, agents, adjusters, public officials, and others to gather data on claim volumes and amounts. The PCS analyzes the data and combines it with trend factors to determine a loss estimate. The PCS also maintains a database containing information on the number and types of structures for every US state. 
to the PCS data. We then estimate the loss quantiles to measure exposure to loss from various perils.

Prior to fitting probability distributions, it is important to adjust the PCS loss data for changes in the value of property exposed to loss. The reason for this adjustment is that the value of property exposed to loss in the United States expanded dramatically during the period from 1949 through 2006, both from growth in the housing stock and price appreciation. Consequently, events from prior decades would be likely to cause much greater damages if they occurred today. To adjust the data for changes in property values, we created an exposure index for each state using the US Census Bureau's decennial Census data on housing values. ${ }^{24}$ Values for years between the decades are calculated based on logarithmic interpolation; values for 2001 to 2006 are calculated based on the annual growth rate that prevailed from 1990 to 2000. This series gives the aggregate value of owner-occupied homes for each state in nominal dollars, so an increase in these figures over time represents both more houses being built and increases in the price level. The index is computed simply as the ratio of the 2006 value in a given state to the value in a past year:

$$
\text { ExposureIndex }_{\text {state }}^{\text {year }}=\frac{\text { AggregateHomeValue }_{\text {state }}^{2006}}{\text { AggregateHomeValue }_{\text {state }}^{\text {year }}} .
$$

Then, the nominal loss value reported by the PCS for a given catastrophe in a given year and state is multiplied by the value of the exposure index for that year and state. This is an estimate of the losses a past catastrophe would cause if it occurred today, considering present price levels and the size of exposed infrastructure. ${ }^{25}$

Because the PCS focuses on insured losses from catastrophic events, we also adjust the PCS data to estimate the total (insured and uninsured) losses from each event. These adjustments differ by peril, because the proportion

Using that information, the PCS can estimate the number of insurable risks in a specific geographic area. Combined with survey information, the structure data forms the basis for the PCS damage estimates. For large or unusual events, the PCS resurveys the affected insurers to obtain updated information. The PCS estimation methodology is described in more detail in Property Claims Services (2006).

24. The series used is: H024, AGGREGATE VALUE. Universe: specified owner-occupied housing units, defined by the Census Bureau as the "total number of owner occupied housing units described as either a one family home detached from any other house or a one family house attached to one or more houses on less than 10 acres with no business on the property. The data for 'specified' units exclude mobile homes, houses with a business or medical office, houses on 10 or more acres, and housing units in multi-unit buildings."

25 . The use of a housing value index implicitly assumes that the value of commercial property and automobiles exposed to loss has expanded at the same rate as the value of residential property. Because population growth in a geographical region is likely to be accompanied by corresponding growth in commercial activity and the number of automobiles, this is likely to be a reasonable assumption. The use of housing values implicitly assumes that the value of land as a proportion of total housing value remains more or less constant over time. This assumption is potentially important, because storm damages are to structures and other property rather than to land, whereas the value of land is incorporated in the value of the housing stock. 
of property covered by insurance varies significantly by peril. For example, earthquake insurance take-up rates in California are substantially smaller than homeowners insurance take-up rates in the Southeast. These adjustments are described in detail next.

For hurricane/tropical storm, thunderstorm, and winter storm losses, we scale up the losses by a constant factor - the inverse of the ratio of insured to total loss for the corresponding peril in our federal expenditure sample (with NFIP losses not included in the insured figure).

Similarly for earthquakes, we use known take-up rates for earthquake insurance since 1996 for California (available from the California Department of Insurance) and project earlier take-up rates based on the relationship between annual California earthquake premium data (also from the California Department of Insurance), California aggregate housing value, and the known take-up rates since $1996 .{ }^{26} \mathrm{We}$ apply the inverse of these known and estimated take-up rates to the PCS insured earthquake loss for the year it occurs to get a total loss figure.

\subsubsection{Statistical Methodology}

To estimate an aggregate annual claims distribution, we use a Fast Fourier Transform (FFT) inversion method. The approach requires separate estimates of the severity of loss and annual frequency of occurrence distributions for each specific peril. We then compound these estimates to produce distributions of aggregate annual claims by peril and for all catastrophes.

Thus, the estimation has five phases: ${ }^{27}$

1. Estimate the severity of loss and annual frequency distributions separately for each of the major catastrophe perils using maximum likelihood estimation.

2. Discretize the severity distribution by dividing the full range of possible loss into equal segments and placing all the probability within a segment at its midpoint.

3. Apply the FFT to the discretized severity distribution to obtain its characteristic function.

4. Transform this characteristic function using the estimated frequency

26. Take-up rates since 1996 are from the California Department of Insurance (http://www .insurance.ca.gov/0250-insurers/0600-data-reports/0100-earthquake-cov-exp/). Annual earthquake premium data were obtained by fax from Richard Roth Jr. at the California Department of Insurance.

27. The reason for applying the Fast Fourier Transform approach is that the total claims distribution cannot be computed by convoluting the severity random variables and then compounding the convolutions with the frequency distribution for most realistic frequency and severity distributions. However, the total claims distribution can be recovered by computing and then inverting the characteristic function. The FFT approach is discussed in Klugman, Panjer, and Willmot (2004). The severity distributions are discretized using the rounding method on 4,096 segments of $\$ 100$ million of loss. Any further tail probability, corresponding to losses exceeding $\$ 409.6$ billion (number of segments $\bullet$ loss per segment), is placed on the last point of the discretized severity probability density function. 
distribution, yielding the characteristic function of the aggregate annual claims distribution.

5. Apply an inverse FFT to recover the aggregate annual claims distribution functions. ${ }^{28}$

For fitting the severity of loss data, three different distributions are used, which have been shown to provide good models of loss distributions in prior research (e.g., Cummins et al. 1990; Cummins, Lewis, and Phillips 1999). The distributions - the lognormal, the Pareto, and the Burr 12 - are specified as follows.

The lognormal:

$$
f(x)=\frac{1}{x \sigma \sqrt{2 \pi}} e^{-(1 / 2)\{[\ln (x)-\mu] / \sigma\}^{2}}, x>0 .
$$

The Pareto:

$$
f(x)=\alpha \lambda^{\alpha}(\lambda+x)^{-\alpha-1}, x>0 .
$$

The Burr 12:

$$
f(x)=|a| q x^{a-1} b^{-a}\left[1+\left(\frac{x}{b}\right)^{a}\right]^{-q-1} .
$$

We use the Poisson distribution, specified as follows, to fit the annual occurrences of a given peril over our sample period, 1950 to 2005.

The Poisson:

$$
f(x)=e^{-\lambda} \frac{\lambda^{x}}{x !}, x=0,1,2 \ldots
$$

\subsubsection{Results}

Summary statistics on catastrophe losses are presented in table 4.3 , which have been adjusted for changes in housing exposures, both from growth in the housing stock and price level increases (but not to account for differences between insured losses and total losses). All data are from the PCS. Hurricanes have the highest average and median loss severity at $\$ 8.8$ billion and $\$ 1.2$ billion, respectively. Hurricanes also have the highest standard deviation of loss. As expected, the observed losses are highly skewed for all perils.

The trends in the total number of catastrophic events and the total insured losses are shown in figure 4.7. The loss amounts have been adjusted to 2006 property values, and catastrophes that would not have caused at least $\$ 25$ million in losses at 2006 property value levels have been deleted for purposes of preparing this figure. Even though Hurricane Katrina was the largest loss event recorded during the sample period in nominal dollars, based on

28. This implicitly assumes that losses from catastrophe perils such as hurricanes, tornadoes, and earthquakes are statistically independent. The calculation utilizes the result that the characteristic function of the sum of independent random variables is the product of the characteristic functions of the individual random variables in the sum. 


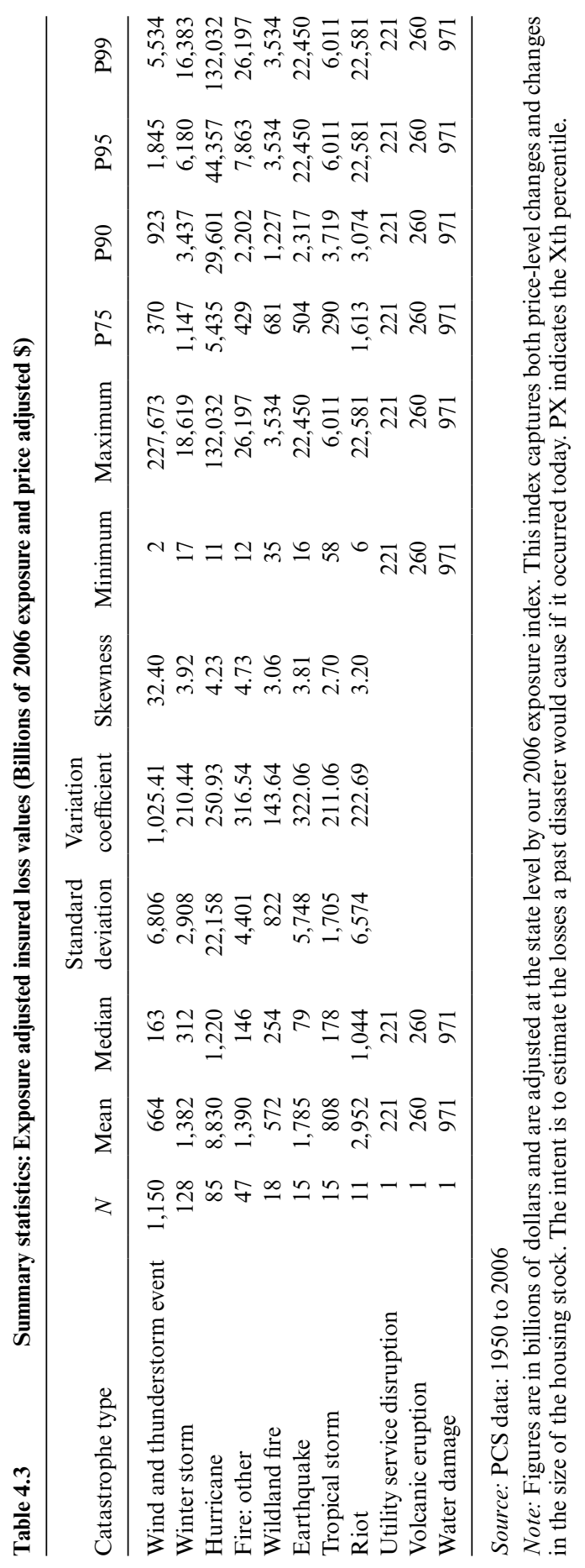




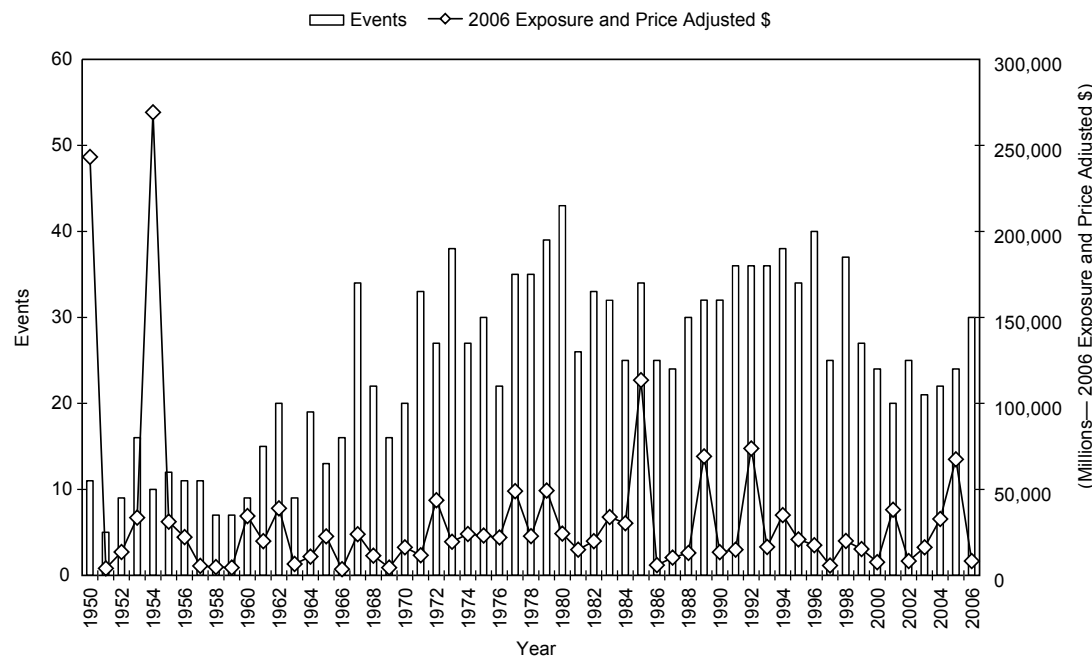

Fig. 4.7 PCS aggregate insured loss: Threshold of \$25 million by event

Note: Figures are adjusted at the state level by our 2006 exposure index. This index captures both price-level changes and changes in the size of the housing stock. The intent is to estimate the losses a past disaster would cause if it occurred today.

the housing value-adjusted loss data, there were five previous events of approximately equal or greater magnitude. In 1950, a major wind and thunderstorm event caused substantial property losses from Maryland to Maine. If a similar event occurred at present, the estimated losses would be greater than $\$ 227$ billion. In 1954, Hurricane Carol caused major damage ranging from New Jersey to Maine, with particularly large losses in Massachusetts and New York. The same year, Hurricane Hazel caused devastating losses ranging from South Carolina to New York. If those storms occurred today, it is estimated that Carol and Hazel would cause losses of $\$ 132$ billion and $\$ 125$ billion, respectively. A storm of the magnitude of Hurricane Gloria, which struck several northeastern states in 1985, would cause estimated losses of $\$ 65$ billion if it occurred today. By contrast, insured losses from Hurricane Katrina were "only" $\$ 44$ billion.

Parameter estimates for the various distributions and perils are shown in table 4.4, along with log-likelihood function values. Estimates are shown both for insured and total losses. The last column of the table shows the best-fitting distribution based on an approximate likelihood ratio test. ${ }^{29}$ The Pareto provides the best fit for all perils except earthquake.

29. The likelihood ratio test results are only approximate, because the distributions estimated are not nested in the sense that they can be obtained by imposing parameter restrictions on the distribution with the largest number of parameters. The significance tests are based on a chi-square distribution with 1 degree of freedom. The likelihood test statistic is $2 \cdot[\log (L: \operatorname{distribution} 1)-\log (L:$ distribution 2$)]$ for pairwise tests of the distributions. 


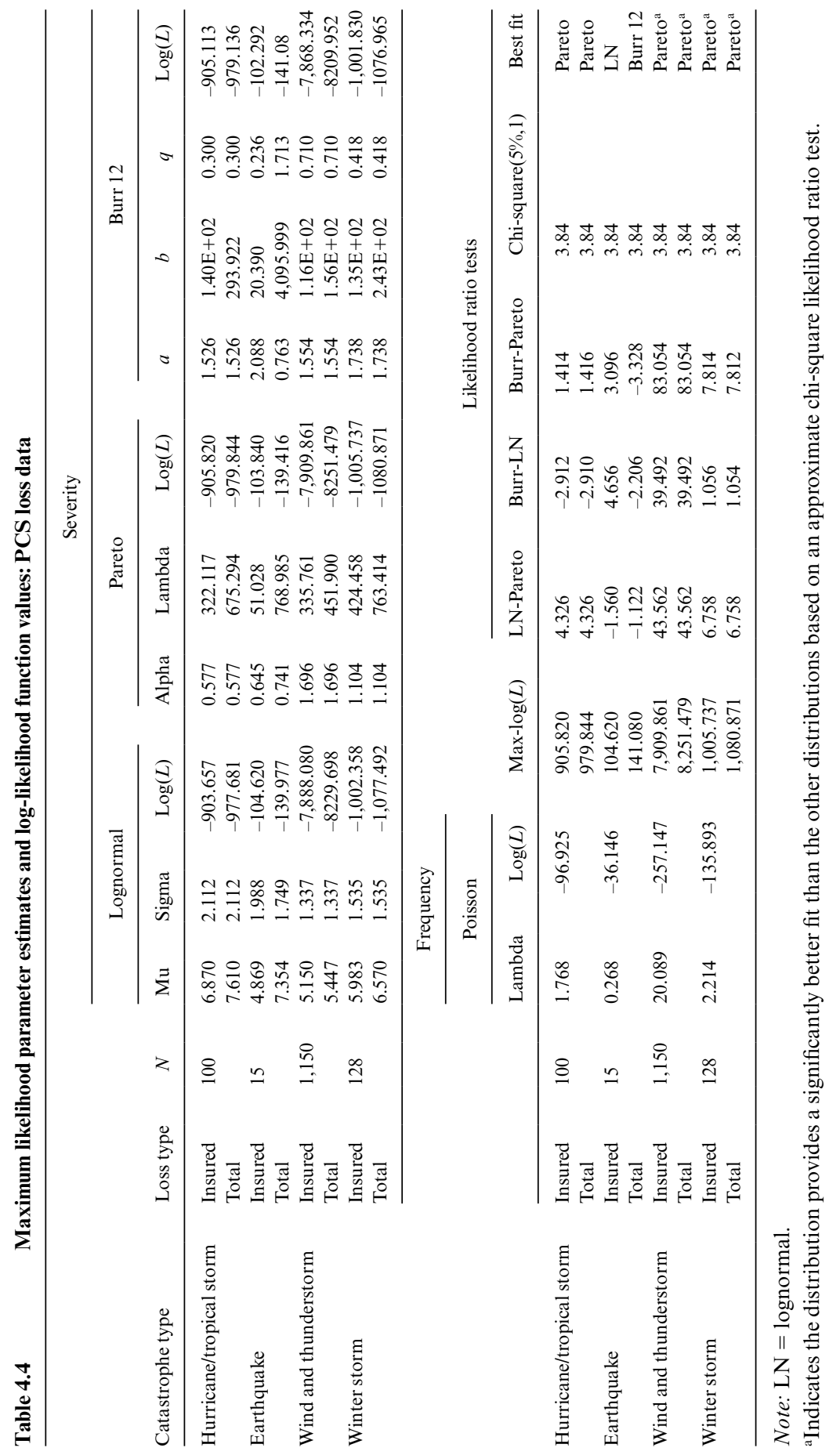


As an example of one of the estimated distributions, the severity distribution of total losses from hurricanes and tropical storms is shown in figure 4.8. The likelihood ratio results show that the Pareto provides the best fit to this set of data but not at a high level of statistical significance. The graph bears this out but suggests that all three distributions fit the data reasonably well, with the Pareto and Burr 12 perhaps overestimating the probability in the tail of the distribution. In figure 4.9, we present the annual aggregate claims distribution of total losses for all perils. These distributions are not directly estimated from the data. They are derived by compounding the separately estimated severity and frequency distributions for each individual peril through the FFT method described previously. Due to computational limitations, all three distributions are capped at $\$ 409.6$ billion, leading to underestimation of probability in the tail of the distribution.

Table 4.5 presents the means and upper percentiles of the estimated severity of loss distributions for the models whose parameters are shown in table 4.4. The percentiles shown are the 50th, the 75th, the 90th, the 95th, the 99th, and the 99.9th. The latter three percentiles would correspond to event "return periods" of twenty, one hundred, and one thousand years, respectively.

In table 4.6, we present annual aggregate losses by peril and for all perils (hurricanes, earthquakes, wind and thunderstorms, and winter storms) combined. For all perils, we project an expected annual insured loss range of 24 to 35 billion dollars and a total loss range of 39 to 48 billion dollars. The ninety-ninth percentiles of the insured and total loss distributions are 181 to 310 billion dollars and 272 to 337 billion dollars, respectively. These estimates suggest very large exposure to catastrophic losses for both the government and the insurance industry.

\subsection{Estimated Annual Losses and Projected Liabilities}

The AIR model projects expected annual catastrophe total losses of 35 to 43 billion dollars; this is roughly comparable to the projections from the PCS data, which indicate annual average losses of 39 to 48 billion dollars. For the ninety-ninth percentile, the AIR model indicates insurable loss of 273 to 282 billion dollars, which is again comparable to the total loss figures from the PCS methods - which indicate a range from 272 to 337 billion dollars, depending on the distribution chosen.

Reasonable estimates of the recent relation between federal aid and losses, based on the analysis presented, range from 30 percent to 50 percent - with figures at the higher end of the range supported by generosity observed in recent events such as the 2005 hurricanes and by the aggregated ratios of aid to losses over the period. It is true that the aggregates are skewed to some degree by the larger events that have happened in recent years, but even a straight average, by event, of the ratio of aid to loss yields a figure in excess of 30 percent. 


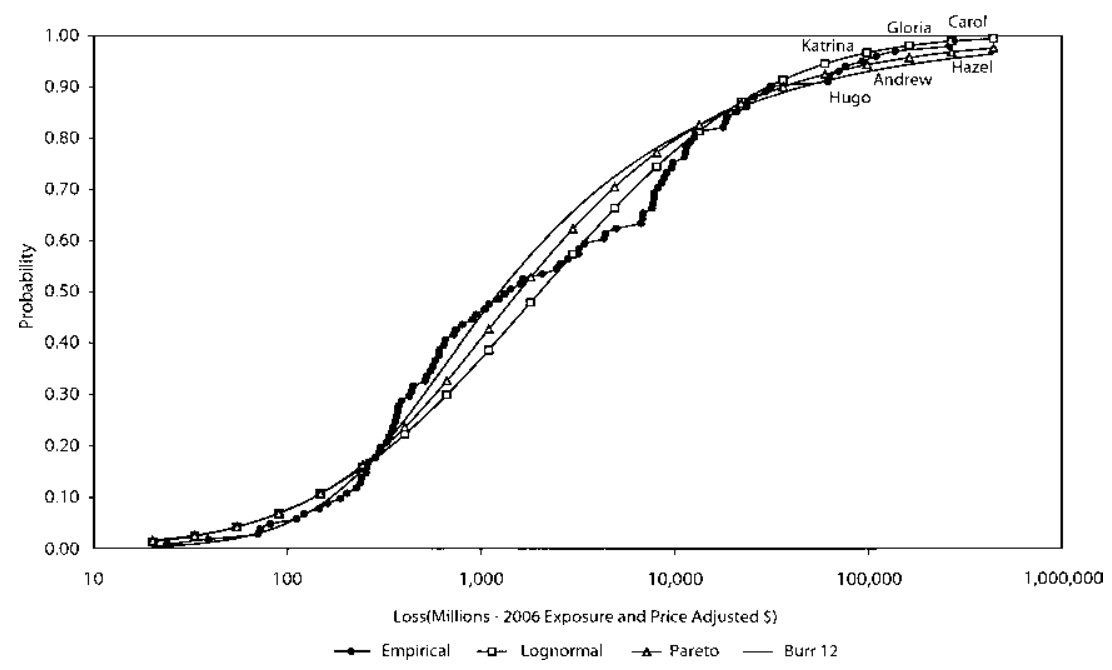

Fig. 4.8 Hurricane/tropical storm occurrence severity: Total loss

Note: The data used in this estimation were adjusted at the state level by our 2006 exposure index. This index captures both price-level changes and changes in the size of the housing stock. The intent is to estimate the losses a past disaster would cause if it occurred today.

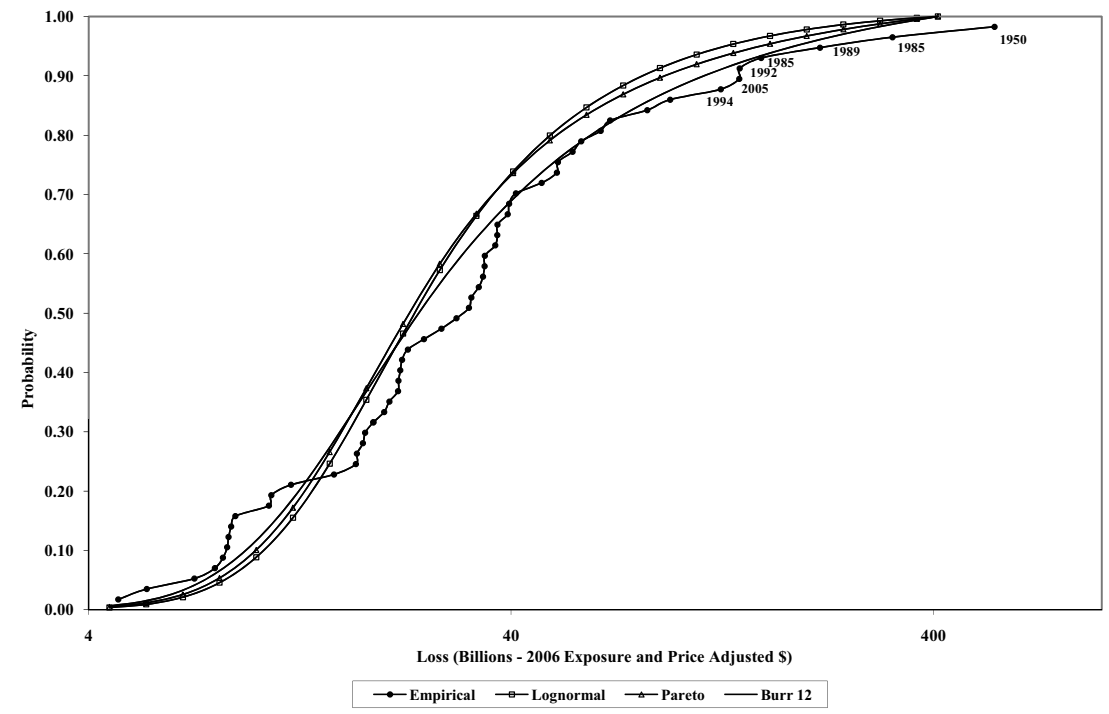

Fig. 4.9 All perils annual aggregate claims: Total loss

Note: The data used in this estimation were adjusted at the state level by our 2006 exposure index. This index captures both price-level changes and changes in the size of the housing stock. The intent is to estimate the losses a past disaster would cause if it occurred today. 


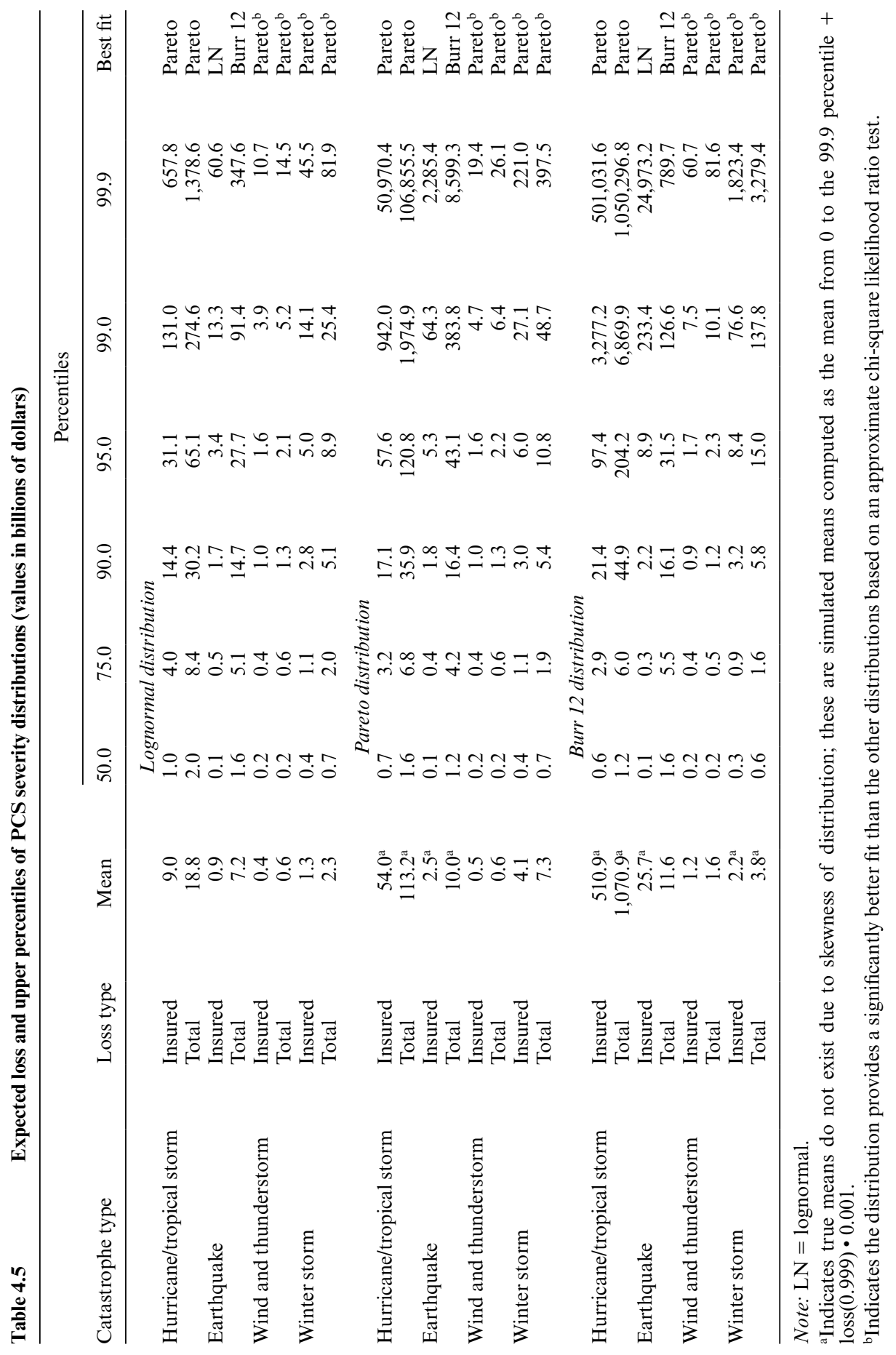


Table 4.6

Expected loss and upper percentiles of aggregate annual claims distributions (values in billions of dollars)

\begin{tabular}{|c|c|c|c|c|c|c|c|c|}
\hline \multirow[b]{2}{*}{ Catastrophe type } & \multirow[b]{2}{*}{ Loss type } & \multirow[b]{2}{*}{ Mean } & \multicolumn{6}{|c|}{ Percentiles } \\
\hline & & & 50.0 & 75.0 & 90.0 & 95.0 & 99.0 & 99.9 \\
\hline \multicolumn{9}{|c|}{ Lognormal } \\
\hline \multirow[t]{2}{*}{ Hurricane } & Insured & 12.5 & 2.0 & 9.3 & 29.6 & 56.7 & 175.8 & 391.5 \\
\hline & Total & 22.2 & 4.3 & 19.2 & 58.8 & 108.1 & 275.2 & 409.4 \\
\hline \multirow[t]{2}{*}{ Earthquake } & Insured & 0.2 & 0.0 & 0.0 & 0.1 & 0.7 & 4.5 & 26.7 \\
\hline & Total & 1.8 & 0.0 & 0.0 & 2.5 & 7.4 & 36.1 & 165.6 \\
\hline \multirow[t]{2}{*}{ Wind and thunderstorm } & Insured & 8.4 & 7.4 & 10.2 & 13.7 & 16.4 & 24.0 & 41.1 \\
\hline & Total & 11.4 & 10.0 & 13.8 & 18.5 & 22.2 & 32.4 & 55.4 \\
\hline \multirow[t]{2}{*}{ Winter storm } & Insured & 2.8 & 1.1 & 3.1 & 6.7 & 10.5 & 24.7 & 67.8 \\
\hline & Total & 5.1 & 2.0 & 5.6 & 12.2 & 19.0 & 44.4 & 120.6 \\
\hline \multirow[t]{2}{*}{ All perils } & Insured & 23.6 & 14.4 & 23.7 & 43.9 & 70.0 & 180.6 & 355.8 \\
\hline & Total & 39.4 & 23.5 & 41.7 & 81.7 & 128.4 & 271.8 & 388.4 \\
\hline \multicolumn{9}{|c|}{ Pareto } \\
\hline \multirow[t]{2}{*}{ Hurricane } & Insured & 16.7 & 1.5 & 7.7 & 34.1 & 84.4 & 324.3 & 409.4 \\
\hline & Total & 24.5 & 3.1 & 15.1 & 60.9 & 134.4 & 383.7 & 409.4 \\
\hline \multirow[t]{2}{*}{ Earthquake } & Insured & 0.8 & 0.0 & 0.0 & 0.1 & 0.5 & 8.1 & 246.1 \\
\hline & Total & 3.0 & 0.0 & 0.0 & 1.9 & 6.5 & 60.2 & 409.4 \\
\hline \multirow[t]{2}{*}{ Wind and thunderstorm } & Insured & 9.5 & 7.6 & 10.9 & 15.7 & 20.3 & 39.1 & 117.6 \\
\hline & Total & 12.8 & 10.3 & 14.7 & 21.2 & 27.4 & 52.5 & 152.4 \\
\hline \multirow[t]{2}{*}{ Winter storm } & Insured & 4.2 & 1.0 & 3.1 & 7.8 & 14.4 & 54.5 & 249.0 \\
\hline & Total & 7.0 & 1.9 & 5.6 & 14.0 & 25.6 & 91.5 & 316.9 \\
\hline \multirow{2}{*}{ All perils } & Insured & 28.3 & 14.4 & 25.4 & 55.5 & 101.7 & 268.6 & 390.1 \\
\hline & Total & 42.2 & 22.8 & 42.3 & 92.3 & 155.4 & 315.2 & 397.9 \\
\hline \multicolumn{9}{|c|}{ Burr 12} \\
\hline \multirow[t]{2}{*}{ Hurricane } & Insured & 18.9 & 1.1 & 6.9 & 38.4 & 104.1 & 388.9 & 409.4 \\
\hline & Total & 25.8 & 2.4 & 13.2 & 64.4 & 152.8 & 409.4 & 409.4 \\
\hline \multirow[t]{2}{*}{ Earthquake } & Insured & 1.5 & 0.0 & 0.0 & 0.0 & 0.5 & 15.1 & 409.4 \\
\hline & Total & 2.2 & 0.0 & 0.0 & 2.7 & 8.0 & 41.6 & 254.2 \\
\hline \multirow[t]{2}{*}{ Wind and thunderstorm } & Insured & 13.0 & 7.8 & 12.5 & 22.2 & 34.9 & 104.7 & 306.1 \\
\hline & Total & 17.0 & 10.5 & 16.9 & 29.8 & 46.4 & 132.2 & 330.5 \\
\hline \multirow[t]{2}{*}{ Winter storm } & Insured & 6.5 & 0.8 & 2.9 & 9.8 & 23.1 & 125.9 & 395.8 \\
\hline & Total & 9.7 & 1.6 & 5.2 & 17.2 & 38.8 & 176.4 & 409.4 \\
\hline \multirow[t]{2}{*}{ All perils } & Insured & 34.5 & 15.3 & 31.5 & 78.5 & 142.1 & 309.7 & 397.3 \\
\hline & Total & 47.8 & 24.1 & 49.6 & 114.4 & 187.1 & 337.1 & 401.1 \\
\hline
\end{tabular}

Thus, our analysis suggests an expected annual federal exposure in the neighborhood of 10 to 25 billion dollars, with the exposure in a bad year (once in a century) in the neighborhood of 80 billion to about 170 billion dollars. ${ }^{30}$

These figures have two significant aspects. First, even the low end of our

30. These ranges are rounded figures computed by multiplying the lower bound of our estimates of expected annual catastrophe losses by the lower bound of observed federal aid ratios, 30 percent, and the higher bound of our estimates by the higher bound of observed federal aid ratios, 50 percent. 
expected estimate is substantially higher than current regular appropriations. Second, the projections are accurate enough to be used for determining the size of regular appropriations. As Holtz-Eakins (2005, pp. 18-19) states, "Many analysts believe that current federal budget procedures can lead to inappropriate evaluations of the trade-offs involved in providing assistance and can reduce incentives for mitigation and recovery efforts by state and local governments." He continues that one option, instead of relying so heavily on emergency supplemental appropriations, is to "appropriate money for disaster programs in regular appropriations bills in amounts equal to the expected funding need for each program" (Holtz-Eakins 2005, p. 19). One way of realizing this would be to simply require that the midpoint of our estimate range be budgeted in advance for disaster relief. Then, going forward, projections can be updated fairly easily each year to encompass improvements in catastrophe modeling, revised assumptions about disaster frequency and severity, or changes in expected relief generosity. By aligning policymaker incentives and allowing proper comparison of competing spending priorities, implementing such a system would reduce the substantial future costs of disaster relief. ${ }^{31}$

Assuming our current system of disaster relief is left unreformed, we can compute the net present value of the liability to the Federal Government of disaster spending over a given time horizon (for purposes of comparison with the unfunded liability associated with other social programs). We take the midpoint of our estimate of expected annual spending, $\$ 17.5$ billion. We assume growth in exposure equal to the long-term trend (1950 to 2006) annual growth rate in the value of the US housing stock index, 9 percent. Currently, about $\$ 2$ billion is set aside for disaster aid each year, and we assume this grows with nominal gross domestic product (GDP) based on the same 1950 to 2006 span, which is 7.1 percent. Using a 5 percent discount rate, the net present value of the liability over a seventy-five-year horizon is $\$ 7.1$ trillion. If we assume everything grows at the 5 percent discount rate, the NPV is $\$ 1.2$ trillion. Over this same horizon, the trustees of Social Security project a shortfall with a NPV of $\$ 4.9$ trillion. $^{32}$

\subsection{Concluding Remarks}

The tremendous growth in federal disaster spending observed over the twentieth century has continued in more recent years. The $\$ 82$ billion in

31. Of course, challenges arise when shifting to explicit recognition of expected disaster relief in the budget. In particular, bureaucratic motivations to overspend on particular disasters would have to be addressed. On the other hand, it is debatable whether an official budgetary acknowledgment of this entitlement, based on current levels of generosity, would encourage or restrain further growth in generosity.

32. "The present value of future tax income minus cost, plus starting trust fund assets, minus the present value of the ending target trust fund amounts to $-\$ 4.9$ trillion for the OASDI program" (see SSA [2006, p. 57]). Available at: http://www.ssa.gov/OACT/TR/TR06/. 
emergency federal spending on Katrina and other proximate hurricanes in 2005 exceeded the fiscal year (FY) 2005 budget of all but five government agencies, as well as the total amount appropriated for the muchmaligned Congressional earmarks. ${ }^{33}$ Our analysis shows that the expected annual expenditure on disaster assistance - an estimated 10 to 25 billion dollars - is quite significant and could be even higher if more aggressive assumptions that put a greater weight on recent trends are used. While this estimate is obviously not precise, different assumptions or methods seem unlikely to alter the basic inferences about the significance of the annual cost.

The cost is indeed significant: given the current approach to disaster relief funding, we project an "unfunded" liability for disaster assistance over the next seventy-five years comparable to that of Social Security. The current annual budget of FEMA falls far short of expected annual federal disaster assistance, most of which is financed through supplemental appropriations on an "as needed" basis. Over the period from FY1989 to FY2006, FEMA's Disaster Relief Fund received original appropriations for less than $\$ 15$ billion while experiencing outlays of over $\$ 58$ billion (Bea 2006).

This budgetary treatment may not be unusual, but the lack of transparency with respect to acknowledging the commitment and accounting for its size is unfortunate in at least two respects. First, the costs and benefits of the disaster assistance program currently cannot be weighed against other national priorities. Second, federal disaster policy itself cannot be optimized without understanding the commitment and the dollars involved. For example, if a scaling back of the federal disaster assistance program is not politically realistic, federal subsidization of state and local mitigation expenditures may be in the taxpayers' interest—at least in the short run. Our projections make explicitly incorporating expected relief spending in the regular budgeting process a real possibility. Doing so would force the informed decision making that will optimize relief, although such incorporation would have to be combined with careful consideration of spending authority and bureaucratic incentives to insure that spending is ultimately restrained.

In designing disaster relief policy, there are many important considerations that we do not attempt to analyze. Notably, many have observed that disaster assistance embodies a "samaritan's dilemma" in the sense of its presence encouraging development in high-risk areas. Implicit in our approach is the notion that prior to probing the deeper implications of the economic incentives embedded in disaster relief policy, it makes sense to

33. The agencies were Health and Human Services (HHS; Medicare), Social Security, Defense, Treasury (debt interest), and Agriculture (Winters 2006). The FY2005 earmarks totaled approximately $\$ 50$ billion (CRS Appropriations Team 2006). 
first ask how extensive it is. Thus, we have attempted to measure and document the financial extent of current policy, with the belief that reform and management must be informed by measurement.

We document that disaster assistance is a large and continuous liability to the Federal Government, which increases with the value of infrastructure exposed to catastrophes. Though we are accustomed to think of catastrophes as unpredictable, our analysis demonstrates that it is possible to forecast expected future costs for disaster assistance. Knowing the magnitude of these figures can inform both the budgeting process and, ultimately, the design of disaster relief policy.

\section{References}

Bea, K. 2006. Federal Stafford Act disaster assistance: Presidential declarations, eligible activities, and funding. Congressional Research Service (CRS) Report for Congress, Order Code RL33053. Washington, DC: CRS.

Bram, J., J. Orr, and C. Rapaport. 2002. Measuring the effects of the September 11 attack on New York City. Federal Reserve Bank of New York Economic Policy Review 8 (2): 5-20.

Chite, R. M. 2006. Emergency funding for agriculture: A brief history of supplemental appropriations, FY1989-FY2006. CRS Report for Congress, Order Code RL31095. Washington, DC: CRS.

Clark, K. M. 2004. Catastrophe modeling: Assessing and managing risk. In Reinsurance: Fundamentals and new challenges, 4th ed., ed. R. Gastel. New York: Insurance Information Institute.

Congressional Research Service (CRS) Appropriations Team. 2006. Earmarks in appropriation acts: FY1994, FY1996, FY1998, FY2000, FY2002, FY2004, FY2005. Congressional Research Service Memorandum. Washington, DC: CRS.

Cummins, J. D. 2006. Should the government provide insurance for catastrophes? Federal Reserve Bank of St. Louis Review 88 (4): 337-79.

Cummins, J. D., G. Dionne, M. Pritchett, and J. B. McDonald. 1990. Applications of the GB2 family of probability distributions in collective risk theory. Insurance: Mathematics and economics 9 (4): 257-72.

Cummins, J. D., C. M. Lewis, and R. D. Phillips. 1999. Pricing excess-of-loss reinsurance contracts against catastrophic loss. In The financing of catastrophe risk, ed. K. A. Froot, 93-149. Chicago: University of Chicago Press.

Dunham, W. B. Jr., and J. Dembeck. 2008. U.S. Terrorism Risk Insurance Act extended for seven years. Real Estate Finance 24:19-20.

Federal Crop Insurance Corporation. 2007. Summary of business report for 2004 through 2007. Available at: http://www.rma.usda.gov/data/sob.html.

Federal Emergency Management Agency (FEMA). 2006. Watermark: National Flood Insurance Program 2006 (2). Washington, DC: FEMA.

Hartwig, R. 2008. Financial crisis: Private and public sector impacts. Presentation to the Southeastern Regulators Association Conference. 20 October, Orlando, Florida.

Holtz-Eakins, D. 2005. Macroeconomic and budgetary effects of Hurricanes Katrina 
and Rita. Congressional Budget Office (CBO) Testimony before the Committee on the Budget, US House of Representatives. Washington, DC: CBO.

Jenkins, W. O. Jr. 2006. Federal Emergency Management Agency: Challenges facing the National Flood Insurance Program. Testimony before the Chairman, Committee on Banking, Housing and Urban Affairs, US Senate, GAO-06-174T. Washington, DC: US General Accounting Office.

Klugman, S. A., H. H. Panjer, and G. E. Willmot. 2004. Loss models: From data to decisions. 2nd ed. New York: Wiley-Interscience.

Kunreuther, H., and L. Miller. 1985. Insurance versus disaster relief: An analysis of interactive modelling for disaster policy planning. Public Administration Review 45 (special iss.): $147-54$.

Lott, N., and T. Ross. 2006. Tracking and evaluating U.S. billion dollar weather disasters, 1980-2005. Paper presented at the 86th annual meeting of the American Meteorological Society. 29 January-2 February, Atlanta, Georgia.

Meszaros, J., and M. Fiegener. 2002. Effects of the 2001 Nisqually earthquake on small businesses in Washington state. Washington, DC: US Department of Commerce, Economic Development Administration.

Moss, D. A. 1999. Courting disaster? The transformation of federal disaster policy since 1803. In The financing of catastrophe risk, ed. K. A. Froot, 307-63. Chicago: University of Chicago Press.

- 2002. When all else fails: Government as the ultimate risk manager. Cambridge, MA: Harvard University Press.

Munich Re. 2005. Megacities-megarisks: Trends and challenges for insurance and risk management. Munich, Germany: Munich Re.

— 2008. Topics geo: Natural catastrophes 2007-Analyses, assessments, positions. Munich, Germany: Munich Re. Available at: http://www.munichre.com/ en/publications/default.aspx.

- 2009. Topics geo: Natural catastrophes 2008-Analyses, assessments, positions. Munich, Germany: Munich Re. Available at: http://www.munichre.com/ en/publications/default.aspx.

Murray, J. 2006. Emergency supplemental appropriations legislation for disaster assistance: Summary data FY1989 to FY2006. CRS Report for Congress, Order Code RL33226. Washington, DC: CRS.

Murray, J., and B. R. Lindsay. 2008. Emergency supplemental appropriations legislation for disaster assistance: Summary data, updated October 31, 2008. CRS Report for Congress, Order Code RL33226. Washington, DC: CRS.

Property Claims Services (PCS). 2006. Catastrophe loss estimate procedure description. Jersey City, NJ: Insurance Services Office.

United States Department of Homeland Security (DHS). 2006a. Hurricane Katrina: What government is doing. Washington, DC: DHS.

- 2006b. Quick reference guide for the National Response Plan, version 4.0. Washington, DC: DHS.

United States Government Accountability Office (GAO). 2007. Budget issues: FEMA needs adequate data, plans, and systems to manage resources for day-today operations. Report no. 07-139. Washington, DC: GAO.

United States Social Security Administration (SSA). 2006. 2006 Annual Report of the Board of Trustees of the Federal Old-Age and Survivors Insurance and Disability Insurance Trust Funds. Washington, DC: SSA.

Winters, P. D. 2006. Federal spending by agency and budget function, FY2001FY2005. CRS Report for Congress, Order Code RL33228. Washington, DC: CRS. 